\title{
Investigating effect of short term aging of bitumen with and without Zycotherm-EZ
}

\author{
Mohit R. Korat ${ }^{*}$ and C. B. Mishra \\ Department of Civil Engineering, BVM Engineering College, V.V.Nagar, Anand, India - 388120 \\ Received 01 Feb 2018, Accepted 05 April 2018, Available online 11 April 2018, Vol.8, No.2 (March/April 2018)
}

\begin{abstract}
India is the fastest growing country among developing countries of the world wherein infrastructural growth road development is utmost essential for the country. But with time bitumen becomes more stiff and brittle due to changes in molecular structure of bitumen and increase in viscosity too that adversely affect the performance of pavement as it leads to the crack on pavement, rutting, fatigue cracks, loss of visco-elasticity of binder. To overcome this problem an attempt is made to modify the properties of VG-40 binder by the addition of Zycotherm EZ with suitable dosages. Laboratory investigation is carried out to evaluate the properties of VG-40 binder with and without modifier. Also, effect of heat and air on a moving film of semi-solid binder is determined using RTFOT in accordance with ASTM D 2872 (2006)
\end{abstract}

Keywords: Bitumen Aging, RTFOT, VG - 40 Bitumen, Warm Mixed Additive (WMA), Zycotherm-EZ

\section{Introduction}

Because of increasing request in highway development, researchers and scientists are always attempting to enhance the execution of bitumen pavement. The aging of bituminous covers is one of the key variables deciding the lifetime of pavement. The way toward aging includes chemicals and additionally physical property changes that as a rule make bituminous materials harder and weaker, in this way expanding danger of pavement failure. The aging-related pavement failure modes include cracking (thermal or traffic induced) and raveling. Cracks on pavement surface may expand aging of the fastener in light of increased exposure area to environmental oxygen. The key system; oxidative aging is an irreversible substance response between segments of bitumen and oxygen. It might happen through various responses, for example, photograph oxidation and warm oxidation. The light (fundamentally bright, UV) catalyzed response happens quickly and for the most part happens inside the best $5 \mu \mathrm{m}$ of the uncovered cover film, since bitumen is a decent light safeguard. The photograph oxidation incited aging may have an impact on toughness. The oxidative aging is affected by the substance idea of bitumen likewise on the void substance of black-top blend. In this manner, the oxidative aging of bitumen as capacity of profundity in

*Corresponding author Mohit R. Korat is a M.Tech Transportation Engineering Student (ORCID ID: 0000-0001-9983-6497); C. B. Mishra is working as Associate Professor DOI: https://doi.org/10.14741/ijcet/v.8.2.23 the pavement is firmly identified with void substance of the blend, likewise at a higher temperature aging might be in a general sense unique in relation to aging at bring down temperature that is all the more precisely simulating pavement temperature. The essential targets of this examination are to decide how aging tests (TFOT) under different conditions identify with field aging. In like manner, fresh unmodified and Zycotherm-EZ altered bitumen's were set up for research center aging. Portrayal of binders was performed utilizing customary tests (penetration, softening point),

\section{Literature Review}

B. Hofko, A. Cannone Falchetto, J. Grenfell, L. Huber, X. Lu, L. Porot, L. D. Poulikakos and Z.( 07 Feb 2017) revealed in their study focussing particularly on aging temperatures, as utilized for WMA. The examination of fundamental properties with penetration esteem at $25^{\circ} \mathrm{C}$ and softening point temperature has demonstrated a distinction after RTFOT with various here and now aging temperatures.

Feipeng Xiao, Serji N. Amirkhanian, M.ASCE and Rengen Zhang (2012) revealed the target of their study for examination was to lead a lab examination of rheological properties of warm blend bituminous (WMA) cover after a transient aging technique. Results demonstrated that the WMA added substance can diminish the viscosity estimation of bituminous cover and in this way diminish the blending and compaction temperatures of the blend. 
Suleiman Arafat Yero and Mohd. Rosli Hainin (October 2012) as authors examined the qualities of bitumen penetration review adjusted with commercial additives. The crucial rheological and mechanical tests were led, and result demonstrates that with an expansion in added substance the binder consistency diminishes at high temperature as it solidifies and turns out to be hard at low temperature, in this manner expanding the softening point and decreasing the penetration of binder.

Kishan K.Vachhani and C.B. Mishra (Nov- Dec. 2014) passes on that aging builds the binder hardness; additionally higher estimation of versatile recuperation shows greater adaptability to the fastener and will expand the life of asphalt at low temperature. They used EVA adjusted fasteners for the examination and assessed of here and now aging of bitumen binder utilizing mimicked strategy in the research facility by conditioning a thin film oven test at a high temperature, for a brief span.

Lan Wang, Ghani Razaqpur, Yongming Xing and Gang Chen (15 Feb 2015) have projected the complete examination on impacts of aging on the microstructure and explore the dynamic rheological properties of three changed bituminous. Aging test is done utilizing the RTFOT , it is watched that aging makes every one of the three changed bituminous harder which builds their protection from disfigurement under high temperatures, and declines their exhaustion and cracking resistance at low temperatures.

Kinjal Surti passes on that after TFOT test physical qualities of the bitumen and polymer adjusted bitumen has been changed, subsequently it implicate that softening point will increment while the penetration will diminish after here and now aging with reduce in elastic recuperation too which show that oxidation of altered bitumen had happen and this commitment is because of distinction in temperature.

\section{Innovative Attributes}

\section{Material used}

India has embarked upon massive and unprecedented road construction \& improvement programs involving huge investments. In this study VG 40 grade bitumen with and without Zycotherm-EZ is used.

\section{Paving Grade Bitumen VG 40}

VG-40 is utilized as a part of profoundly focused on areas, for example, crossing points, close toll booths and truck parking garages in lieu of old 30/40 Penetration review. Because of its higher Viscosity, stiffer Bitumen blends can be created to enhance resistance to shoving and other issue related with higher temperature and overwhelming traffic activity loads. The materials are obtained from Tiki tar Industry, Vadodara, Gujarat.

Zycotherm-EZ
Zycotherm EZ is an organosilane additive to bitumen binder, to be added before bitumen is mixed with aggregates to produce WMA. ZT-EZ makes the pavements resistant to:

- Moistures it promotes chemical bonding at the aggregate interface

- Oxidation, as it enables complete coating

- Fatigue loads, as it facilitates consistent compaction while paving

Moreover, ZT-EZ also allows lower mixing temperatures (by $10-15^{\circ} \mathrm{C}$ ) and lower compaction temperatures (by $30-40^{\circ} \mathrm{C}$ ), making ZT-EZ an environment friendly warm mix, warm compaction additive.

\section{Devising of Polymer Modified Bitumen:}

For the study under investigation 2000 gram of VG 40 bitumen is added at temperature $160^{\circ} \mathrm{C}$ in suitable dosages of $0.075,0.100$ and $0.125 \%$ by weight of binder to blend the mix using mechanical stirrer to 15 min. to make a homogenous mixture. Different physical test has been carried out on the base as well as polymer modified bitumen such as viscosity test, penetration test, softening point test and ductility test which help to determine the property of binder before and after Rolling Thin-Film-Oven-Test to check the changes after short term aging.

\section{Rolling Thin-Film Oven Test (RTFOT)}

Rolling Thin Film Oven Test (RTFOT) is only the reproduction of maturing condition amid blending and compaction. In the event that material shows great bendable qualities after RTFOT, it infers that binder can be laid pleasantly out and about and won't age (deteriorate) much amid blending and compaction. Bituminous mix with and without ZY-EZ in suitable dosages is exposed to raised temperatures $163^{\circ} \mathrm{C}$ to reproduce assembling and arrangement maturing. The samples in cylindrical glass containers are placed in a rotating machine inside an oven and are rotated for 85 minutes. The RTFOT likewise gives a quantitative measure of the volatiles lost amid the maturing procedure.

\section{Outcome and Discussion}

The test result shows the changes that had been taken place in the physical property of the base bitumen and polymer modified bitumen before and after the RTFOT test as shown in Table 1:

The results shows after addition of additive Zycotherm-EZ with various dosages in the bitumen VG40 sudden physical change has been seen in the binder both in terms of before and after aging too. 
Table 1 Physical Properties of VG 40 Bitumen with and without Additive (RTFOT)

\begin{tabular}{|c|c|c|c|c|c|c|c|}
\hline Binder type & $\begin{array}{l}\text { softening } \\
\text { point }\left({ }^{\circ} \mathrm{C}\right)\end{array}$ & $\begin{array}{l}\text { penetration } \\
(\mathrm{mm})\end{array}$ & $\begin{array}{c}\text { viscosity } \\
\left(135^{\circ} \mathrm{c}\right)\end{array}$ & $\begin{array}{c}\text { Ductility } \\
(\%)\end{array}$ & $\begin{array}{c}\text { Flash \& } \\
\text { Fire point }\end{array}$ & $\begin{array}{l}\text { Specific } \\
\text { Gravity }\end{array}$ & $\begin{array}{c}\text { Loss on } \\
\text { Heating (\%) }\end{array}$ \\
\hline Codal Provision & Min.50 & Min.35 & Min.400 & Min.25 & Min.220 & $>1$ & $<1$ \\
\hline \multicolumn{8}{|c|}{ Before aging } \\
\hline VG 40 & 54.50 & 38.33 & 652 & 96 & 330 & 1.037 & 0.11 \\
\hline VG $40+$ ZY-EZ $0.075 \%$ & 55 & 38.05 & 587.5 & 98 & 335 & 1.029 & 0.05 \\
\hline VG $40+$ ZY-EZ $0.100 \%$ & 58.50 & 37.5 & 585 & 100 & 338 & 1.01 & 0.04 \\
\hline VG $40+$ ZY-EZ $0.125 \%$ & 56.50 & 37.83 & 607 & 100 & 339 & 1.003 & 0.07 \\
\hline \multicolumn{8}{|c|}{ After aging } \\
\hline VG 40 & 58 & 36 & 661.2 & 94 & 310 & 1.037 & 0.1 \\
\hline VG $40+$ ZY-EZ $0.075 \%$ & 56 & 35 & 545 & 96 & 318 & 1.029 & 0.21 \\
\hline VG $40+$ ZY-EZ $0.100 \%$ & 55 & 34 & 574.5 & 97 & 326 & 1.01 & 0.25 \\
\hline VG $40+$ ZY-EZ $0.125 \%$ & 55 & 34 & 621 & 96 & 329 & 1.003 & 0.35 \\
\hline
\end{tabular}

As the concentration of modifier increases the properties such as softening point increases, fire point increases, penetration decreases and Ductility increases. Increases in softening point indicate that modified bitumen resist the permanent deformation as decrease in penetration determines the hardness and stiffness of binder too. Increase in the ductility value indicates the flexibility of binder and increase the life of pavement too. The loss in weight on heating to lose volatility is also within the permissible limit. The oxidation process seen after RTFOT states that improvement in properties is seen which is fruitful too.

\section{Conclusions}

This paper concludes a successful way of outcome of laboratory study depicting that VG $40+$ ZY-EZ $0.1 \%$ dosage of zycotherm EZ enhance all the physical properties of VG 40 bitumen before and after aging too. The reorientation of properties is witnessed as a part of high temperature and substantial activity zones and states the climatic conditions in which it ought to be utilized usefully. It has got the opportunities for highway segment building organizations.

\section{References}

ASTM D 2872 - Effect of heat and air on moving film of bituminous (RTFOT)

B. Hofko, A. Cannone Falchetto, J. Grenfell, L. Huber, X. Lu, L. Porot, L. D. Poulikakos and Z. 07 Feb 2017. Effect of shortterm ageing temperature on bitumen properties. s.l. : Road Material and Pavement Design,
Feipeng Xiao, Serji N. Amirkhanian, M.ASCE, and Rengen Zhang. 2015. Influence of Short-Term Aging on Rheological. s.l. : American Society of Civil Engineers

Hainin, Suleiman Arafat Yero \& Mohd. Rosli. October 2012. Evaluation Of Bitumen Properties Modified With Additive. s.l. : International Journal of Research and Reviews in Applied Sciences, October 2012.

IS: 1202- 1978, Methods for testing tar and bituminous materials: determination of specific gravity.

IS: 1203- 1978, Methods for testing tar and bituminous materials: determination of penetration.

IS: 1205- 1978, Methods for testing tar and bituminous materials: determination softening point.

IS: 1206- 1978, Methods for testing tar and bituminous materia. ls: determination of viscosity.

IS: 1208-1978, Methods for testing tar and bituminous materials: determination of Ductility

IS: 1209-1978- Determination of Flash Point and Fire Point.

IS: 1212-1978 -Determination of Loss on Heating.

Kinjal Surti \& Prof. C.B.Mishra (2016), Evaluating the Effect of Modified Bitumen after Short-Term Aging using FTIR Spectroscopy. s.l.: International Journal for Research in Applied Science \& Engineering Technology.

Kishan K.Vachhani, Prof. C.B. Mishra. Nov- Dec. 2014. Assessing the impact of VG30 grade bitumen with and without additive (EVA) on short term aging. s.l. : Journal of Mechanical and Civil Engineering, Nov-

Lan Wang, Ghani Razaqpur, Yongming Xing and Gang Chen. 15 Feb 2015. Microstructure and rheological properties of aged and unaged polymer-modified asphalt binders. s.l. : Road Material and Pavement design 